\title{
Recent advances in keratoplasty
}

\author{
DEREK AINSLIE \\ London \\ Contributed by request and dedicated to Sir Stewart Duke-Elder
}

To Zirm (1906) is attributed the honour of having performed the first successful penetrating keratoplasty. For years before this, the possibility of transplanting a clear cornea in place of an opaque one had fascinated ophthalmologists, but attempts, using both human and animal tissue, had been universal failures. Nevertheless, the pioneer work of von Hippel (1888) developed instruments for keratoplasty which formed the basis of those used today. He set the course for great achievements a century later.

It was in the I 920 s that the true foundation of modern keratoplasty was laid by Elschnig (1930) in Prague, and it is strange that his work is so little remembered. To almost every ophthalmologist, Elschnig's name is eternally associated with "pearls" because of his delightful description of the swollen epithelial remains after extra-capsular cataract extraction. Few recall that he performed I 79 penetrating keratoplasties before I930 (Elschnig, I930). Of these, only 39 remained perfectly clear, but he showed that the operation was a reasonable proposition and that good results could be obtained. Considering the fact that most of his cases were near to hopeless, that instruments were simple in the extreme, and that antibiotics and steroids to combat infection and inflammation were non-existent, his results were remarkable indeed.

During the I930s, corneal transplantation steadily gained ground, through the efforts of Castroviejo (1932, 1934) in the United States and Tudor Thomas (1933, 1934) in the United Kingdom, both of whom had performed clinical corneal transplants by the early thirties. Immediately after the second world war, Paufique in France further advanced keratoplasty, stressing particularly the value of lamellar transplants (Paufique, 1946).

Lamellar keratoplasty, so admirable in suitable cases, is very much under-rated even today. Both in lamellar and penetrating keratoplasty, simplicity of technqiue was the keynote of success, a point stressed by Leigh (1954).

As the advantages of antibiotics and corticosteroids became available, these simple methods began to yield really good results in suitable cases. During the immediate postwar period, indirect methods of fixation were almost universal. These methods are now seldom used, but much can be learned from considering past results. Usually cross-over sutures of 6/o silk in various patterns were used, but several surgeons, notably Seymour Philps, believed that a splint of plastic was more effective (Philps and Fincham, 1952). After Philps's death, I continued to use his splint, modified in a variety of ways, and have performed over a hundred grafts by this method. Even today, when a small graft is required, as for example in a very heavily vascularized cornea, I still believe that this is the best technique. The minimal trauma to a transplanted material is of supreme importance and will be considered in greater detail later.

Gradually, as instruments and materials for suturing have improved, the indirect methods of fixation have given way to the direct, but it must be remembered that, if these 
more secure, but inevitably more traumatic, methods are to be successful, damage to the graft must be minimized. Many failures attributed to poor donor material or other exigencies are due to surgical damage to the new corneal tissue, especially the endothelium. Edge-to-edge interrupted sutures were described at the Ophthalmological Society of the United Kingdom Meeting by José Barraquer Moner (1949).

Barraquer was instrumental in the development of needles fine enough for the relatively atraumatic insertion of fine silk sutures. Since his description of edge-to-edge direct suturing of penetrating grafts, instruments have continued to improve, enabling technical successes with much larger grafts, and the scope of keratoplasty has therefore increased to cover a much wider range of conditions. These changes have, however, produced new problems: greater liability to vascularization, greater vulnerability of the graft to uveitis, and therefore greater risk of rejection.

\section{Penetrating transplants}

Fixation

(I) INDIREGT

(a) Cross-over sutures This method no longer has any place in penetrating keratoplasty, but can be of value in lamellar work.

(b) Splint fixation This is suitable only for grafts up to $6.5 \mathrm{~mm}$. in diameter. However, small grafts such as these do have a place as a final procedure where a heavily vascularized cornea has been treated by a preliminary larger lamellar transplant. These small grafts are particularly valuable after a satisfactory tectonic result of a lamellar graft in a case of chemical corneal burn. In such cases a small graft is much more likely to remain clear and the absence of suture trauma will not only decrease the chances of vascularization, but reduce the distorting effect of sutures placed so close to the visual axis.

(2) DIRECT

With the introduction of the beautifully delicate, sharp-pointed disposable needles, this method has become the most generally useful. The needles may be obtained bonded to fine 8/o silk and to many forms of monofilament nylon, usually 10/0 in size.

\section{(a) Interrupted sutures}

(i) 8/o silk This has the advantage of being very easy to use but it fragments during its period in $\cong$ the tissues and is difficult to remove. Also it produces a substantial reaction. This reaction may be $\frac{I}{O}$ harmful in that it produces vascularization, but useful in so far as it increases the rapidity of the healing process. Silk should therefore never be used in cases in which the cornea is already vas- Oo cularized, but it can be of value where healing is liable to be slow and indifferent, in particular in keratoconus.

(ii) Monofilament nylon (Perlon, Ethilon) ro/o gauge monofilament nylon is excellent suture material. Great care is required during its insertion, not only to avoid breaking it, but to obtain the correct tension at each suture. Interrupted monofil sutures, deeply placed, and with the suture pulled through to bury the knot in the needle track, provide one of the safest forms of suturing for a penetrating graft. Irritation from the sutures is of a very low order and suture removal is simple.

\section{(b) Continuous sutures}

The continuous suture has the advantage of providing very even tension between host and graft, and its purse-string effect reduces the chances of anterior chamber leakage. 
Every bite must, however, be very sound, otherwise loosening of the whole suture may occur prematurely with serious consequences.

(i) Silk These are not now frequently employed, though they may be useful in keratoconus, providing the advantage of the even pull of the continuous suture with the greater stimulation to healing than is obtained with nylon.

(ii) Monofilament nylon These provide the least irritating form of direct suturing and, inserted accurately, give firm and safe fixation. The suture must be tight enough to assure maintenance of the anterior chamber, but the common fault of pulling it too tight must be avoided. Too tight a continuous suture not only distorts the graft edges, but increases the liability of a loop to cut out.

\section{(c) Combination of interrupted and continuous sutures}

(i) Silk interrupted with continuous Perlon Before a continuous suture is inserted, at least four interrupted direct sutures should be placed to steady the graft. These may be removed at the conclusion of the continuous suture, or left in place. If the latter course is taken, they provide additional initial security, but the silk becomes quite loose after Io days or so and may easily be removed at this stage.

(ii) Interrupted and continuous, both of Perlon In this method, four or more interrupted Perlon sutures should be inserted, depending upon the size of the graft and how well it lies after the insertion of the first four. A continuous suture should be interdigitated with the interrupted, one or two bites being taken between each interrupted suture. After the continuous suture has been completed, the knots of the interrupted sutures should be buried in the transplanted material. This method is very secure and embodies the advantages of both interrupted and continuous suturing with a minimal increase in the irritation produced.

\section{(d) Double continuous suture of Perlon}

The insertion of two continuous sutures has been advocated as being more secure than a single one. The second suture is inserted in the opposite direction from the first. I have no personal experience of this technique, but Troutman (I97 I) considers it to be an excellent method.

\section{Precautions while inserting direct sutures}

The most vulnerable part of the cornea is the endothelium and damage to the endothelium will certainly result in a failed graft. The indirect fixation method allowed the placement and securing in position of the transplant without any trauma to the endothelium. It is for this reason that donor material several days old consistently gave clear grafts in the early days. The endothelium of an eye stored at $4^{\circ} \mathrm{C}$. does not spontaneously become non-viable for many days, but it does become swollen and soft, and easily strips off at the slightest touch. Even very fresh endothelium may be damaged by rubbing against the underlying iris. In the case of many water-logged grafts, where the blame has been placed upon unhealthy donor material, the true cause has been damage to the endothelium during the placement of the direct sutures. This form of trauma must be prevented, since not only is the endothelium irreparably damaged, but iris trauma may lead to uveitis, iris atrophy, and a permanently dilated pupil. This is a particular risk where the eye contents tend to bulge during the operation, as in keratoconus, and is the probable cause of the syndrome of uveitis in iris atrophy and secondary glaucoma, described as a special danger in grafts performed for keratoconus.

An essential precaution in all grafts where the eye seems likely to bulge, should be the 
prophylactic use of an intravenous hypotensive, such as mannitol or urea. General anaesthesia is also of the utmost value. In all cases, before removing the corneal disc from the recipient eye, two cross-over sutures should be placed from limbus to limbus. These can be tied immediately the corneal transplant is in place. These sutures hold the graft firmly in position and prevent the sliding movements which inevitably lead to endothelial and iris damage during the insertion of the edge-to-edge sutures. The cross-over sutures must remain in place until at least four direct sutures are in position. Jones and Rice (1969) have advocated the formation of the anterior chamber by air following the insertion of the initial cross-over sutures, thereby making for more accurate suturing since the eye takes up its definitive shape. It may also decrease further any possible trauma to the endothelium.

\section{The Graft}

\section{OBTAINING THE DONOR DISC}

Donor material for penetrating keratoplasty should be as fresh as possible, but corneal tissue obtained within 24 hours and stored at $4^{\circ} \mathrm{C}$. is satisfactory if the precautions during suturing outlined above are observed.

Care must also be taken in the cutting of the donor disc. In addition to preserving the endothelium, the edges must be even and square cut. It is difficult to assure such a perfect cut when trephining the donor cornea directly as is done with the recipient cornea. Sometimes the edges of the disc are found to be oblique or uneven. A worse complication is the unrecognized separation of a small crescent of Descemet's membrane near the periphery. Should a disc in which this has occurred be used, a persistent area of oedema at the edge of the graft will result. These problems can be avoided if the whole cornea, along with a small rim of sclera, is removed and placed inverted in an excavation in a block of paraffin wax.

The disc is punched from the posterior surface with the same trephine as is used to cut the recipient. This method assures a perfect cut and a perfect fit. The movement with the trephine through the disc results from straight pressure. The trephine must not be rotated.

\section{GHOIGE OF SIZE OF GRAFT}

Mention has been made of the use of a small graft in cases of heavily vascularized corneae where reasonable improvement has been previously obtained by a preliminary lamellar transplant. Grafts of 6 or $7 \mathrm{~mm}$. are also satisfactory for diffusely scarred corneae, where the corneal tissue is nevertheless relatively normal. Larger grafts are required where there are substantial areas of diseased, degenerate, or thinned cornea. In active diseases, such as herpes, an attempt must be made to remove all the diseased area. Postoperative rejection can occur after any graft, but the risk is at its lowest with small transplants. The risk does not increase markedly up to $8 \mathrm{~mm}$., but every small increase above this size leads to a large increase in the danger. An immunological reaction of greater or lesser severity will occur in most $9 \mathrm{~mm}$. grafts and in all $10 \mathrm{~mm}$. grafts. Over $10 \mathrm{~mm}$. the immunological reaction is always very severe and technical problems due to the proximity of the drainage apparatus of the eye add further complications.

The ideal size for a penetrating graft would appear to be about $7 \mathrm{~mm}$., and if larger grafts are required, the smallest possible consistent with removing the unhealthy portion of the cornea should be performed. Wherever possible, when a penetrating graft of over $8 \mathrm{~mm}$. appears to be indicated, the alternative possibility of a large lamellar graft followed by a small penetrating graft should be examined. 


\section{SURGERY}

\section{IRIDEGTOMY}

The presence of anterior synechiae will necessitate in many cases an extensive iridectomy, though occasionally the synechiae can be stripped away and the need for iridectomy avoided. One or more peripheral iridectomies should be performed in all cases where anterior synechiae have been present. Iridectomies should also be performed in every case with evidence of uveitis, such as posterior synechiae.

\section{POSTOPERATIVE GOURSE}

Ideally, at the first dressing, usually performed 24 hours after the operation, the grafted tissue should appear clear. All that is permissible without giving cause for anxiety, is a little folding of Descemet's membrane. It is sometimes stated that it is not a serious matter for a graft to be cloudy for a few days. It is true that such grafts may clear, but more often the final result is unsatisfactory. Furthermore, this phenomenon indicates that damage has occurred to the endothelium and often suggests unsatisfactory technique.

\section{GOMPLICATIONS}

\section{Postoperative oedema}

This is always the result of defective or damaged endothelium and, unless minimal, will not clear. Should corneal oedema persist for a week, nothing is to be gained by further hopeful waiting, so the graft should be removed and replaced. The homograft reaction which may look similar to endothelial damage, appears during the third postoperative week and is usually preceded, sometimes unnoticed, by uveitis. Vascularization may occur but is not an essential precursor of the homograft reaction. The clinical manifestations are due to endothelial degeneration, causing stromal and epithelial oedema. Once the endothelium has degenerated, it will not recover, so recognition of the earliest sign of a homograft reaction is very important. Signs of uveitis occurring around the third week, however slight, must be viewed with concern and intensive corticosteroid therapy applied. Slight corneal oedema, which is a further indication of the danger, is reversible if treated early. Corticosteroids are best applied topically in the form of dexamethasone $0 \cdot 1$ per cent., with additional subconjunctival triamcinolone. Systemic corticosteroid administration is rarely required. It cannot be over-stressed that persistent uveitis is fatal to the success of a corneal transplant. Even in cases of herpes simplex where active herpes recurs, the steroids must not be stopped in the presence of uveitis. The herpes must be treated with I.D.U. or $F_{3} T$, or even carbolization, while the steroids are continued.

\section{Anterior synechiae}

These may result from incarceration of iris in the wound at the time of operation, but in most cases they follow an anterior chamber leak. In general, the presence of anterior synechiae is unsatisfactory and the position should be rectified. Should a synechia be found in the early postoperative period, unless it is very broad, or unless an anterior chamber leak is present, it is usually best left alone initially, and divided at the time of suture removal. Careful stuturing followed by re-formation of the anterior chamber with Ringer's or balanced salt solution, at the end of the operation, is the best prophylaxis.

\section{Postoperative anterior chamber leaks}

These are usually the result of faulty suturing but, whatever the cause, the leak must be 
closed immediately by re-suturing. Synechiae should be divided and the anterior chamber re-formed, preferably with air.

\section{GORNEAL OPAGITIES AND GATARAGT}

Contrary to past practice, where cataract and corneal opacities co-exist it is best to perform the corneal transplant and cataract extraction at the same operation. If extraction is performed after the keratoplasty, it must be delayed for at least a year and even then endothelial degeneration may occur in the graft. If preoperative mannitol or urea is given intravenously, there is little danger of vitreous loss occurring during the procedure. To facilitate the delivery of the lens, it is wise to use a graft of $8 \mathrm{~mm}$. in diameter. The pupil should be semi-dilated, at least one iridectomy performed and the lens delivered using the cryoprobe. The use of zonulolysin is indicated.

Before the lens is removed, the donor cornea should be transferred to the recipient and four interrupted sutures inserted at 12, 6, 3, and 9 o'clock. The lower suture should be fully tied, the other three half tied and left loose. The cornea is turned well back during the lens delivery to avoid any possible damage to the donor endothelium. Immediately after delivery, the cornea is placed in the recipient aperture and the three remaining sutures tied. Miotic is introduced into the anterior chamber and a continuous suture of monofilament is inserted. In such cases the anterior chamber should be re-formed with air.

\section{PENETRATING KERATOPLASTY IN APHAKIC EYES}

This is a satisfactory procedure but special precautions must be taken to avoid vitreous loss, especially when the vitrous face is already broken. Mannitol or urea is given and the cornea trephined as for a lamellar graft. A vitreous aspiration is performed at this stage via the pars plana. The corneal disc is then removed, using first a knife to enter the anterior chamber and then scissors to complete the section. The donor disc is placed and secured in the normal manner, first with cross-over sutures, then interrupted, and finally continuous. The anterior chamber is then re-formed with air. Many surgeons prefer to aspirate vitreous through the pupil, but the pars plana method seems to be more satisfactory. It is far better to avoid vitreous prolapse than to treat it.

Should vitreous come forward despite the precautions outlined above, extensive anterior vitrectomy must be performed. The new cornea must on no account be placed in position until it is certain that no vitreous remains anterior to the iris. Grafts in aphakic patients are facilitated if a Flieringa ring is used, but the ring should not be too large; I 3 to I4 $\mathrm{mm}$. diameter is ideal for maintaining a round corneal aperture.

\section{Lamellar keratoplasty}

This is indicated in cases of superficial corneal opacities and often as a preparatory measure in severely damaged corneae.

\section{REASONS FOR USE}

\section{(I) TEGTONIC}

In heavily vascularized corneae, a large preliminary lamellar graft is invaluable as a method of improving the general condition of the cornea, and providing satisfactory tissue in which a smaller penetrating graft has a reasonable chance of surviving and remaining clear. The method is especially valuable in eyes damaged by caustic burns. It is also useful as a 
method of building up the thickness where the cornea is thinned over a wide area. Although the transplanted lamella rapidly adheres sufficiently to be secure from dislocation, it is important to realize that really firm adherence does not occur for at least 12 months. It is therefore essential not to proceed to a penetrating graft until this period has elapsed after the initial lamellar graft.

\section{(2) REPLAGEMENT OF LOST TISSUE}

Lamellar grafts may be used after the excision of limbal neoplasms, especially limbal dermoids, and limbal melanomata, and in cases of Bowen's disease.

\section{(3) OPTICAL GONSIDERATIONS}

Lamellar keratoplasty can give very good optical results in suitable cases. The operation carries so much less danger than penetrating keratoplasty that it should be considered in all cases where the opacities appear to be superficial. A good optical result, however, can only be obtained if the bed of the graft consists of healthy corneal tissue. If, during the section of the lamellae, it is found to be impossible to dissect deep to the diseased area, it must be decided whether to complete the operation as a lamellar graft and to perform a smaller penetrating graft later, or whether to change straight away to a penetrating keratoplasty. The decision does not need to be made before starting the operation, and will depend upon the actual appearance of the graft bed and the size of the lamellar graft being performed.

\section{SURGIGAL TEGHNIQUE}

In most cases opacities will extend fairly deeply into the stroma and the recipient tissue will be removed by trephining the outline with a trephine set to the correct depth followed by dissection of the bed, using a flat dissector of the Troutman type.

The donor disc may be obtained in a similar manner. However, a disc with a much smoother surface can be fashioned with an electrokeratome. The Castroviejo electrokeratome produces satisfactory results, but an even more accurate cut is obtainable with the Barraquer microkeratome, developed for refractive keratoplasty (Barraquer Moner, I967a).

The visual results in a lamellar graft will depend upon the smoothness of the interface surfaces, and preferably both host and donor surfaces should be perfectly smooth. Even if one perfect surface is obtained, however, the visual result will be greatly enhanced. Therefore the electrokeratome method is useful in obtaining donor material in all lamellar keratoplasties. If the opacities do not involve more than half the corneal thickness, and ir the corneal surface is reasonably smooth, the microkeratome can be used both for obtaining the donor material and for removing the tissue from the recipient. This assures two perfect surfaces to form the interface. Approximately 20 per cent. of cases requiring lamellar keratoplasty are suitable for this method.

\section{Suturing}

Little need be added to the methods described under penetrating keratoplasty. However in general, four to eight interrupted sutures of nylon are the best in lamellar work. They should not be tied very tightly, since they are only present to stop the disc from dislocating during eye movement. Indeed, cross-over sutures can be very satisfactory in lamellar keratoplasty. 
Of great importance, however, is postoperative pressure to make certain that the graft is pressed well into apposition with its bed. A pressure bandage should be applied at the end of the operation and left undisturbed for 3 days, to ensure precise union between the donor and the host. Pressure should be maintained for 2 weeks.

\section{Refractive keratoplasty}

Many methods of altering the refractive power of the cornea by incisions and resections have been described (Sato, Akiyama, and Shibata, 1953), but only in keratomileusis and keratophakia can the degree of correction be carefully controlled (Barraquer Moner, $1967 \mathrm{~b}$ ).

\section{(A) KERATOMILEUSIS}

In this operation a parallel-sided disc usually $8.0 \mathrm{~mm}$. in diameter and $0.35 \mathrm{~mm}$. thick is removed from the cornea using the Barraquer microkeratome (Barraquer Moner, r967a).

This disc is placed upon a lathe equipped with freezing apparatus. After freezing, a lenticule of corneal stroma of the same power but of the opposite sign to the refractive error, is carved from the posterior surface of the disc. Keratomileusis is usually performed in the correction of myopia and therefore a positive lenticule is removed. When the disc is replaced on the eye the central area of the cornea is thinned and the diameter of the anterior corneal surface is increased. The factor limiting the amount of myopia correctable by this method is the initial thickness of the cornea. In a cornea $0.55 \mathrm{~mm}$. thick, about I 8 dioptres of myopia can be corrected safely.

\section{Indications}

Unilateral myopia, where spectacles or contact lenses prove impossible or unsatisfactory, is the major indication. Especially encouraging results have been obtained in overcoming amblyopia and achieving fusion in children with unilateral myopia, but painstaking orthoptic treatment is required postoperatively. The operation is rarely indicated in bilateral myopia in young people.

\section{(B) KERATOPHAKIA}

In this procedure, intended to correct hypermetropia, a convex lenticule of substantia propria of correct power is carved from donor cornea. A parallel-sided disc is removed from the patient's cornea in the same way as in keratomileusis. The new lenticule is inserted between the elevated disc and the bed of the cornea and the disc is sutured in place using a continuous nylon suture. The effect is to reduce the radius of curvature of the anterior corneal surface and thereby to correct the hypermetropia.

\section{Indications}

The main indication is unilateral hypermetropia, particularly when of high degree, as in aphakia. Its greatest use is in the treatment of unilateral traumatic aphakia in young children. Several cases of aphakia consequent upon congenital cataract have also been treated, but while improvement has been obtained in some the amblyopia is usually too dense to improve.

The above is a brief general account of the methods of keratomileusis and keratophakia as used in the correction of high refractive errors. Further details can be obtained by those interested from the following authors (Barraquer Moner, 1949, 1967, 1969; Ainslie, 1956, 1959, 1969; Ainslie and Mathalone, r972; Littmann, I967). 


\section{Summary}

(I) A review of important milestones in keratoplasty is given.

(2) Various techniques of performing penetrating and lamellar keratoplasty are described. Particular attention is paid to the precautions necessary to reduce complications, both operative and postoperative.

(3) The treatment of co-existing cataract and corneal opacities is described.

(4) A brief review of refractive keratoplasty is included.

\section{References}

AINSLIE, D. (1956) Trans. ophthal. Soc. U.K., 76, 49I

$$
\begin{array}{ll}
\text { (I959) Ibid., 97, } 209 \\
\text { (1959) Ibid., 89, } 647
\end{array}
$$

and mathalone m. B. R. (1972) Arch. Soc. Amer. Oftal. Optom., 9, $3^{\text {I }}$

BARRAQUER MONER, J. I. (1949) Trans. ophthal. Soc. U.K., 69, 77

- (1949) Estud. Inform. oftal., 2, no. 1o (Dec.)

- (1967a) Arch. Soc. Amer. Oftal. Optom., 6, 2 I

- (1967b) Ibid., 6, 69

- (1969) In "Corneo-plastic Surgery," ed. P. V. Rycroft, p. 409. Pergamon Press, Oxford CAstroviejo, R. (I932) Amer. F. Ophthal. 15, 825

(1934) Ibid., 17, 932

elschnig, A. (1930) Arch. Ophthal. (Chicago), 4, 165

hippel, A. von (1888) v. Graefes Arch. Ophthal., 34, 108

JONES, B. R., and RICE, N. S. C. (1969) In "Corneo-Plastic Surgery", ed. P. V. Rycroft, p. 307. Pergamon

Press, Oxford

LEIGH, A. G. (1954) Brit. F. Ophthal., 38, ro

Littmann, H. (1967) Arch. Soc. Amer. Oftal. Optom., 6, I03

PHILPS, A. S., and FINCHAM, E. F. (1952) Trans. ophthal. Soc. U.K., 72, 2 I

PAufiQue, L. (1946) Bull. Soc. franf. Ophtal., 59, 96

SATo, т., AKIYAMA, K., and shibata, H. (1953) Amer. F. Ophthal., 36, 823

thomas, J. w. TUdor (1933) Proc. roy. Soc. Med., 26, 597

- (1934) Ibid., 28, 195

troutman, R. C. (I97I) Personal communication

ZIRM, E. (I906) Ibid., 64, 58 I 